\title{
Contraceptive use by Iranian women with hypertension, diabetes or obesity
}

M. Nojomi, ${ }^{7}$ N. Morrovatdar, ${ }^{7}$ F. Davoudi ${ }^{7}$ and S. Hosseini ${ }^{7}$

$$
\begin{aligned}
& \text { استخدام موانع الحمل لدى الإيرانيات المصابات بارتفاع ضغط الدم أو بالسكّري أو بالسِّمنة } \\
& \text { مرضية نجومي، نكار مروت دار، فرنوش داو داودي، سحر حسيني }
\end{aligned}
$$

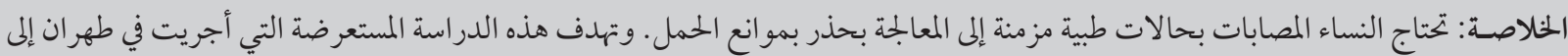

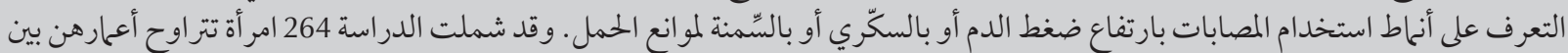

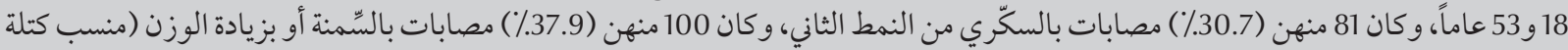

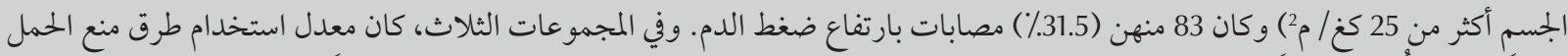

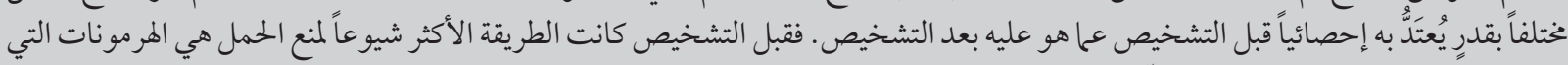

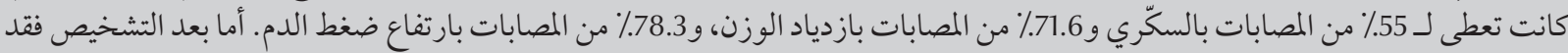

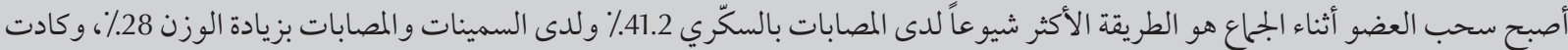

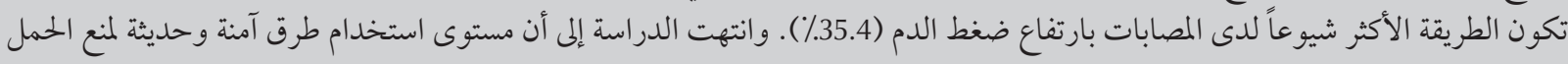

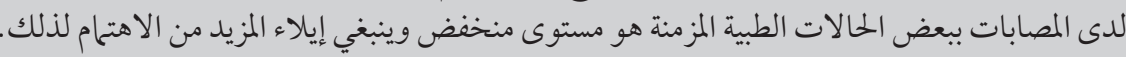

ABSTRACT Women with chronic medical conditions require careful contraceptive management. The aim of this cross-sectional study in Tehran was to determine the pattern of contraception use by women with diabetes, hypertension or obesity. A sample of 264 women aged 18-53 years old was recruited; 81 (30.7\%) had diabetes type 2, $100(37.9 \%)$ were obese/overweight (BMI > $\left.25 \mathrm{~kg} / \mathrm{m}^{2}\right)$ and $83(31.5 \%)$ had hypertension. Across all 3 groups, the rate of use of contraceptive methods was significantly different before and after diagnosis. Before diagnosis of disease the most common method was hormonal contraception in all women $(55.0 \%, 71.6 \%$ and $78.3 \%$ of diabetic, overweight and hypertensive women respectively), whereas after diagnosis coital withdrawal was the most common method in diabetic and obese/overweight women ( $41.2 \%$ and $28.0 \%$ respectively) and almost the most common method for hypertensive women (35.4\%). Use of safe and modern methods of contraception in women with certain chronic medical conditions was low and needs more attention.

\section{Utilisation de la contraception chez des femmes iraniennes hypertendues, diabétiques ou obèses}

RÉSUMÉ Les femmes atteintes d'affections médicales chroniques ont besoin d'une prise en charge prudente de leur contraception. L'objectif de la présente étude transversale menée à Téhéran était de déterminer les tendances dans l'utilisation de la contraception chez des femmes diabétiques, hypertendues ou obèses. Un échantillon de 264 femmes âgées de 18 à 53 ans a été recruté ; 81 femmes (30,7\%) étaient atteintes d'un diabète de type 2 tandis que 100 femmes (37,9\%) étaient obèses/en surpoids (IMC > $\left.25 \mathrm{~kg} / \mathrm{m}^{2}\right)$ et $83(31,5 \%)$ souffraient d'hypertension. Dans l'ensemble des trois groupes, le pourcentage de recours à des méthodes contraceptives après la pose du diagnostic a considérablement changé par rapport au pourcentage relevé avant. Avant le diagnostic de l'affection, la méthode la plus fréquente était hormonale chez l'ensemble des femmes interrogées (55,0 \%, 71,6 \% et 78,3\% des femmes diabétiques, en surpoids et hypertendues, respectivement), alors qu'après la pose du diagnostic, le retrait coïtal était la méthode la plus fréquente chez les femmes atteintes diabétiques et obèses/en surpoids (41,2 \% et 28,0 \% respectivement) et presque la méthode la plus fréquente chez les femmes hypertendues (35,4\%). L'utilisation de méthodes de contraception sûres et modernes chez les femmes atteintes de certaines affections chroniques était faible. Le sujet mérite que l'on y accorde davantage d'attention. 


\section{Introduction}

Women of reproductive age (15-44 years) are affected by many chronic medical conditions that have important effects on the preconception health of the woman and on pregnancy outcomes $[1,2]$. Chronic conditions such as asthma, hypertension and diabetes may limit the activities of women or lead to them being hospitalized [3]. Obesity is also an increasing health problem. Based on a data from the United States (US), obesity affects $13 \%$ of women aged 18-24 years and 19\% of women aged 24-44 years [4]. Obesity increases the risk of certain morbidities during pregnancy, such as macrosomia, gestational diabetes and pregnancy-induced hypertension [5]. Chronic illness can also affect women's contraceptive choices. Chuang et al. in a qualitative study of women with diabetes, obesity or hypertension aged $18-45$ years in the US reported knowledge deficits about pregnancy-related risks in women with these disorders [6]. They also found that these women were less likely to engage in preconception health promotion and family planning.

A high proportion of eligible women in the Islamic Republic of Iran (78.5\%) use modern contraception [7]. Nevertheless, more than $10 \%$ of married women aged 14-49 years use coital withdrawal as a method of contraception [8] and this rate has been reported to be as high as $17.8 \%$ to $22 \%[7,8]$. Compared with the world average (3\%), it is a high rate of use of the method [8]. It seems that women with chronic medical conditions may select withdrawal as a method of contraception due to fear of side-effects of hormonal contraceptives. Because of the importance of maternal and fetal morbidity and mortality in these women after unwanted pregnancy as a sequence of using an unsafe method of contraception, the current study was carried out to determine the pattern of contraception by diabetic, hypertensive or obese women.

\section{Methods}

\section{Study sample}

In a hospital-based, cross-sectional survey, 300 women with diabetes type 2 , hypertension or overweight/obesity were invited to participate in the study. During 2010, 300 women aged 18-53 years old (reproductive age) attending the teaching hospitals of Tehran University of Medical Sciences were assessed during their visit for selected outpatient diseases. They were selected by a sequential sampling method during the study period. Women were eligible for the present study if they were of reproductive age (18-53 years), had indications for contraceptive use, were sexually active, not pregnant and had a diagnosis of diabetes, hypertension or overweight/obesity. Sexually active women were defined as having a husband in the past 12 months. We defined overweight as body mass index (BMI) between $25-30 \mathrm{~kg} / \mathrm{m}^{2}$, and obesity as BMI $\geq 30 \mathrm{~kg} / \mathrm{m}^{2}$. Hypertension was defined as systolic blood pressure (BP) $\geq$ $140 \mathrm{mmHg}$ or diastolic $\mathrm{BP} \geq 90 \mathrm{mmHg}$ [9]. Diabetes was defined as history of taking insulin or any oral drugs for control of diabetes. A woman was considered as having diabetes if she replied positively to the 2 following questions: "Have you ever been told by your physician that you have diabetes?" Subjects who responded "yes" were then asked: "Do you use any prescription for controlling your diabetes?" We excluded women who refused to participate in the study, illiterate women and subjects with severe physical or mental illnesses. Of the 300 consecutive eligible women, 264 agreed to participate in the study and completed checklists.

\section{Data collection}

The method of collecting data was interview using a structured checklist which had been developed by an extensive literature search and a panel of experts. Pilot interviews were conducted on 15 subjects. Based on the result of these interviews, the checklist was revised. All interviews were conducted in the waiting room of outpatient clinics. All interviewers were medical students who underwent standardized training. The aim of the study was explained to the women. All survey participants were asked about demographic data, medical history and method of contraception used. Demographic variables included age, weight, height, literacy and the number of children. We also asked about the number of abortions and unwanted pregnancies. We asked about recent use of contraceptives and type of contraceptive used before the diagnosis of their disorder. Age was classified into 3 groups for analysis: 18-34 years, $35-44$ years and $45-54$ years.

\section{Statistical analyses}

All statistical analyses were performed using SPSS, version 16. We used frequency tables and percentages for frequency of contraceptive use by type of diseases. The chi-squared test was used for assessing association between contraceptive use, other characteristics of women and type of diseases. Wilcoxon signed ranks test was used to compare frequency of recent and pre-diagnosis type of contraceptive use by women. The significance level was $P<0.05$.

\section{Results}

The characteristics of the study sample of 264 women are illustrated in Table 1. Most women had less than highschool education (46.4\%) and were housewives (84.7\%). They were equally distributed across the 3 age groups (range $33.0 \%$ to $33.7 \%$ ). A majority of women had 2-3 children (57.2\%). Almost one-third of the women (81, $30.7 \%$ ) had diabetes, 83 (31.5\%) were hypertensive and 100 (37.9\%) were obese/ overweight. The median BMI in obese/ overweight women was $28.5 \mathrm{~kg} /$ $\mathrm{m}^{2}$. The most common recently used 


\begin{tabular}{|c|c|c|}
\hline Variable & No. & $\%$ \\
\hline \multicolumn{3}{|l|}{ Type of disease } \\
\hline Diabetes & 81 & 30.7 \\
\hline Hypertensive & 83 & 31.5 \\
\hline Obese/ overweight & 100 & 37.9 \\
\hline \multicolumn{3}{|l|}{ Education } \\
\hline Less than high school & 122 & 46.4 \\
\hline High school graduated & 103 & 39.2 \\
\hline Academic & 38 & 14.4 \\
\hline \multicolumn{3}{|l|}{ Occupation } \\
\hline Housewife & 222 & 84.7 \\
\hline Worker/clerk & 40 & 15.3 \\
\hline \multicolumn{3}{|l|}{ Age (years) } \\
\hline $18-34$ & 88 & 33.3 \\
\hline $35-44$ & 89 & 33.7 \\
\hline $45-55$ & 87 & 33.0 \\
\hline \multicolumn{3}{|l|}{ No. of children } \\
\hline$<2$ & 64 & 24.2 \\
\hline $2-3$ & 151 & 57.2 \\
\hline $4+$ & 49 & 18.2 \\
\hline \multicolumn{3}{|l|}{ Type of contraception (recent) } \\
\hline Withdrawal & 90 & 34.4 \\
\hline Hormonal & 23 & 8.8 \\
\hline IUD & 34 & 13.0 \\
\hline Condom & 43 & 16.4 \\
\hline Tubal ligation/vasectomy & 72 & 27.5 \\
\hline
\end{tabular}

IUD = intrauterine device .

contraceptive method was withdrawal (34.4\%).

Table 2 describes the characteristics of the women by type of disease. The rate of hypertension was greater in women aged $45-54$ years (57.8\%) than younger women $(34.9 \%$ and $7.2 \%$ in women aged $35-44$ and 18-34 years respectively). The highest rate of obesity was among 18-34-year-olds (59.0\%). These differences were statistically significant $(P<0.001)$. The type of contraception use was also significantly different between groups. Withdrawal was the most common method in obese/overweight and diabetic women. Hypertensive women had used a permanent contraceptive method (37.8\%) more than other methods. The second most common method in respectively), whereas after diagnosis of disease coital withdrawal was the most common method in diabetic and obese/overweight women (41.2\% and $28.0 \%$ respectively) and almost the most common method for hypertensive women (35.4\%). The second most common method of contraception was withdrawal (14.8\% and $8.4 \%)$ even before diagnosis of disease in diabetes and hypertensive women. Thus, overall, $11.8 \%(31 / 263)$ of women were using a traditional method of contraceptive (withdrawal) before diagnosis of their disease compared with $34.2 \%$ after diagnosis.

There were significant associations of literacy and number of children with using coitus withdrawal/no method. Women with higher education used withdrawal/no method less than women of other educational levels (13.2\% versus almost $38.0 \%$ ), but women with higher $(\geq 4)$ and lower $(<2)$ numbers of children used the withdrawal method more than women with 2-3 children (almost $38.0 \%$ versus $30.0 \%$ ). We could not find any association between selection of contraception method and other variables.

\section{Discussion} vasectomy (33.8\%) and in obese/overweight women was condoms (23\%). Withdrawal was the second most common method (35.4\%) in hypertensive women $(P<0.001)$.

To investigate whether chronic medical conditions may have affected choice of contraceptives, we compared the pattern of contraception use by women before and after diagnosis of their disease. As we can see in Figure 1 , across all 3 groups, the frequency of use of contraceptive methods were significantly different before and after diagnosis $(P<0.01)$. The most common method was hormonal in all women before diagnosis of disease (55.0\%, $71.6 \%$ and $78.3 \%$ of diabetic, overweight and hypertensive women
In this study of women with hypertension, diabetes or obesity/overweight, our findings showed that the most common contraceptive method used was coitus withdrawal (34.4\%). There was a significant difference in the frequency of use of contraceptive methods before and after diagnosis of chronic disease in these women.

A majority of women were housewives and were less than high-school graduated. Women with diabetes were less educated and the most common method of contraception was withdrawal. Women with hypertensive were more likely to be older, have more children and use tubal ligation/ vasectomy. Obese women were more 


\begin{tabular}{|c|c|c|c|c|c|c|c|}
\hline \multirow[t]{2}{*}{ Variable } & \multicolumn{2}{|c|}{$\begin{array}{l}\text { Diabetes } \\
(n=81)\end{array}$} & \multicolumn{2}{|c|}{$\begin{array}{l}\text { Obesity/overweight } \\
\qquad(n=100)\end{array}$} & \multicolumn{2}{|c|}{$\begin{array}{l}\text { Hypertension } \\
\qquad(\boldsymbol{n}=\mathbf{8 3})\end{array}$} & \multirow[t]{2}{*}{$P$-value } \\
\hline & No. & $\%$ & No. & $\%$ & No. & $\%$ & \\
\hline Education & & & & & & & $<0.001$ \\
\hline Less than high school & 47 & 58.8 & 28 & 28.0 & 47 & 56.6 & \\
\hline High-school graduated & 27 & 33.8 & 46 & 46.0 & 30 & 36.1 & \\
\hline Academic & 6 & 7.5 & 26 & 26.0 & 6 & 7.2 & \\
\hline Occupation & & & & & & & 0.059 \\
\hline Housewife & 70 & 88.6 & 78 & 78.0 & 74 & 89.2 & \\
\hline Worker/clerk & 9 & 11.4 & 22 & 22.0 & 9 & 10.8 & \\
\hline Age (years) & & & & & & & $<0.001$ \\
\hline $18-34$ & 23 & 28.4 & 59 & 59.0 & 6 & 7.2 & \\
\hline $35-44$ & 27 & 33.3 & 33 & 33.0 & 29 & 34.9 & \\
\hline $45-54$ & 31 & 38.3 & 8 & 8.0 & 48 & 57.8 & \\
\hline No. of children & & & & & & & $<0.001$ \\
\hline$<2$ & 17 & 21.0 & 41 & 41.0 & 6 & 7.2 & \\
\hline $2-3$ & 44 & 54.3 & 54 & 54.0 & 53 & 63.9 & \\
\hline $4+$ & 20 & 24.7 & 5 & 5.0 & 24 & 28.9 & \\
\hline Type of contraception (recent) & & & & & & & $<0.001$ \\
\hline Withdrawal & 33 & 41.2 & 28 & 28.0 & 29 & 35.4 & \\
\hline Hormonal & 3 & 3.8 & 15 & 15.0 & 5 & 6.1 & \\
\hline Condom & 12 & 15.0 & 23 & 23.0 & 8 & 9.8 & \\
\hline IUD & 5 & 6.2 & 20 & 20.0 & 9 & 11.0 & \\
\hline Tubal ligation/ vasectomy & 27 & 33.8 & 14 & 14.0 & 31 & 37.8 & \\
\hline
\end{tabular}

IUD = intrauterine device.

educated, had jobs and the most common method of contraception was withdrawal.

In the current study $11.8 \%$ of women reported using a traditional method of contraceptive (withdrawal) before diagnosis of their disease. This rate increased to $34.2 \%$ after diagnosis. We also found that the rate of using the withdrawal method ranged from $28.0 \%$ in overweight to $41.2 \%$ diabetic women. The same rate in another study, performed in the US, was $25.8 \%$ of diabetic women and $20.0 \%$ to $23.4 \%$ of overweight and obese women respectively [10]. These percentages are high and highlight the risks of unwanted pregnancy that these women face due to their contraceptive choices.

This high rate of obese/overweight women $(28.0 \%)$ who did not use any modern method of contraception is concerning. The rate of obesity worldwide is increasing and has more than doubled since 1980. In 2008, 1.5 billion adults aged 20 years and older were overweight, and of these nearly 300 million women were obese [11]. Obesity is known to be an important risk factor for maternal and fetal morbidity and mortality and increased rates of obesity and diabetes in offspring [12-14]. It has been shown that obese women are less likely to use a contraceptive method as compared with women with normal BMI $[10,15]$. Reasons for this are unclear; there may be an assumption that fertility is impaired among obese women or that using certain contraceptives could be dangerous. Nevertheless, it seems contraceptive counselling to assist these women to choose a safe, modern method of contraception is necessary.
Our findings showed that $41.2 \%$ of women with diabetes did not use any modern method of contraception. This rate was $14.8 \%$ before diagnosis of their disease. In the study of Chuang et al. in the US, the rate of contraceptive nonuse was $25.8 \%$ in diabetic women [10]. In another study of diabetic women, the rate of non-use of any contraceptive method was $10.7 \%$ [16] and use of "barrier/natural" methods was $47 \%$. In some studies, it has been shown that overall use of contraceptive methods in diabetic women is similar to that of a comparison group (without diabetes) [16]. The prevalence of diabetes mellitus type 2 is increasing worldwide [17] and three-quarters of people affected by diabetes in developing countries are under 65 years old [18]. Therefore more women of reproductive age have diabetes, with all the accompanying risks 


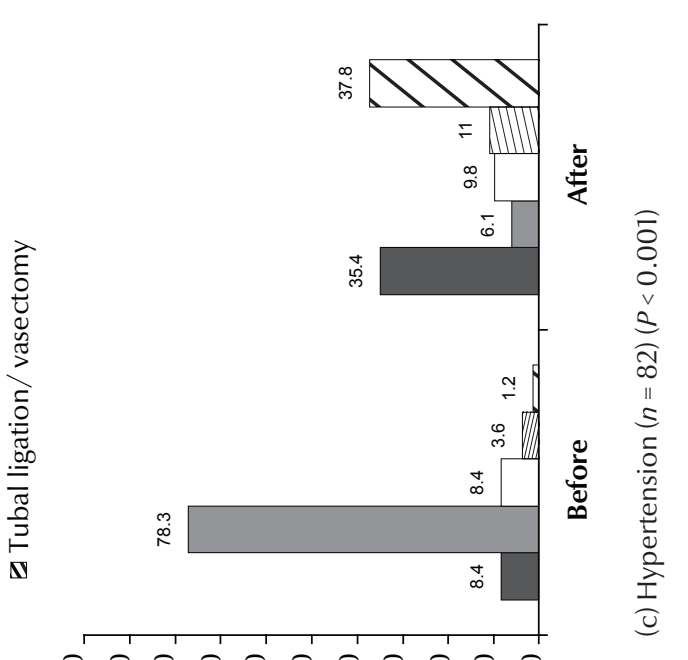

○ \& \& słuəpuodsəx jo \%

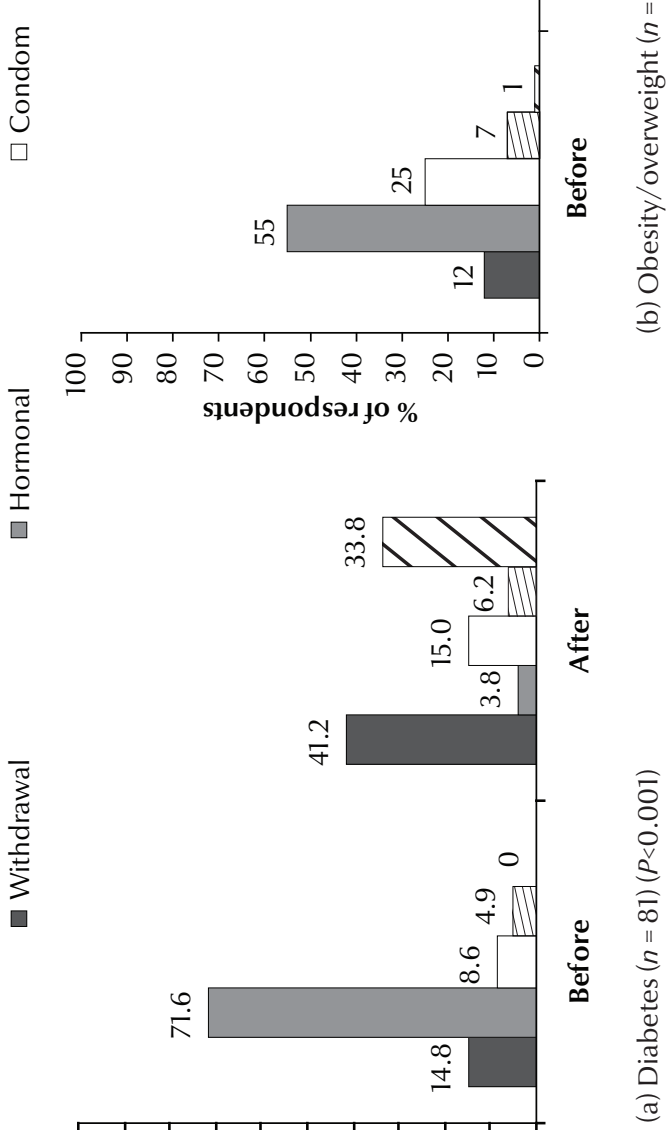

○ คำ słuəpuodsəx jo \% of maternal and fetal mortality and morbidity. As in obese women, there may be many reasons why women with diabetes are less likely to use a safe contraceptive method. Having negative attitudes about contraception, perception of impairment of fertility and lack of proper counselling of diabetic women to choose a safe method of contraception are possible explanations of the high rate of non-use of modern contraception in these women.

We showed that $35.4 \%$ of women with hypertensive disorder did not use any modern method of contraception. Women with chronic medical conditions such as hypertension are of particular concern because of the increased risk for pregnancy-related morbidity and adverse pregnancy outcomes. Our study showed that these women are at increased risk for unintended pregnancy too. To assess how chronic medical conditions influence the intent for pregnancy and family planning behaviours in women, Chuang et al. performed a qualitative study on women ages 18-45 years with diabetes, obesity or hypertension [6]. They reported knowledge deficits about pregnancy-related risks in women with all 3 chronic diseases. They also found these women were less likely to engage in preconception health promotion and family planning.

One weakness of our study was the possibility of recall limitations. We asked about the use of contraceptives before the diagnosis of women's medical conditions and therefore recall bias may have influenced the reliability of data about methods used in the past. On the other hand, our findings showed a clear pattern of changes overall between before and after diagnosis of disorders and a great majority of women had shifted to less risky methods after diagnosis. Another limitation was the small sample size in each group, and we suggest future studies with higher sample sizes. We also suggest future studies on women with medical conditions about types of contraception used, along with assessment of their knowledge and attitudes related to pregnancy, preconception health and family planning. Our work is the first study with this topic in the Islamic Republic of Iran and this is one of the strengths of the current study.

In conclusion, our study showed that use of a safe and modern method of contraception in women with chronic medical condition such as diabetes, hypertension and obesity was low and needed more attention. Since new and safe contraceptive methods are now available, physicians and other health staff should consider women with chronic medical diseases by educating, counselling and suggesting a proper method by each woman's diseases. Through counselling of these women, we can predict lower morbidity and mortality of mothers and improve overall health and quality of life of women with chronic medical condition of reproductive age. 
We also suggest doing such studies in future with larger sample size and focusing on the psychological aspects of using withdrawal as a contraceptive method by couples.

\section{Acknowledgements}

Our special thanks go to the health staff of the teaching hospitals in Tehran for providing us access to the participants. In addition, we would like to thank all the women who took part in and collaborated with the current study.

Competing interests: None declared.

\section{References}

1. Wise PH. Confronting racial disparities in infant mortality: reconciling science and politics. American Journal of Preventive Medicine, 1993, 9(Suppl.):7-16.

2. Misra DP, Grason H, Weisman C. An intersection of women's and perinatal health: the role of chronic conditions. Women's Health Issues, 2000, 10:256-267.

3. Prevalence of Selected Chronic Conditions: United States, 199092 Atlanta, Georgia, Centers for Disease Control and Prevention, 1997 (Vital and Health Statistics, Series 10, No. 194).

4. Schoenborn CA, Adams PF, Barnes PM. Body weight status of adults: United States, 1997-98.. Hyattsville, Maryland, National Center for Health Statistics, 2002 (Advance Data from Vital and Health Statistics No. 330),

5. Crane SS et al. Association between pre-pregnancy obesity and the risk of cesarean delivery. Obstetrics and Gynecology, 1997, 89:213-216.

6. Chuang $\mathrm{CH}$, Velott DL, Weisman CS. Exploring knowledge and attitudes related to pregnancy and preconception health in women with chronic medical conditions. Maternal and Child Health Journal, 2010, 14:713-719.

7. Erfani A. The use of withdrawal among birth limiters in Iran and Turkey. Calverton, Maryland, ICF Macro 2010 (DHS Working Papers No. 71).

8. Aghajanian A et al. Continuing use of withdrawal as a contraceptive method in Iran. Canadian Studies in Population, 2007, 34:179-190.

9. Arquizan C et al.; Patent Foramen Ovale and Atrial Septal Aneurysm Study Group. Blood Pressure, smoking and oral contraceptive control after cryptogenic stroke in young adults in the PFO-ASA Study. Cerebrovascular Diseases, 2005, 20:41-45.
10. Chuang $\mathrm{CH}$ et al. Contraceptive use by diabetic and obese women. Women's Health Issues, 2005, 15:167-173.

11. Obesity and overweight. Fact sheet No. 311. World Health Organization [online] (http://www.who.int/mediacentre/ factsheets/fs311/en/, accessed 16 May 2013).

12. Nohr EA et al. Prepregnancy obesity and fetal death: a study within the Danish National Birth Cohort. Obstetrics and Gynecology, 2005, 106:250-259.

13. Catalano PM, Ehrenberg HM. The short- and long-term implications of maternal obesity on the mother and her offspring. British Journal of Obstetrics and Gynaecology, 2006, 113:1126-1133.

14. Boney $\mathrm{CM}$ et al. Metabolic syndrome in childhood: association with birth weight, maternal obesity, and gestational diabetes mellitus. Pediatrics, 2005, 115:e290-e296.

15. Cohen SS et al. Obesity and screening for breast, cervical, and colorectal cancer in women: a review. Cancer, 2008, 112:1892-1904.

16. Napoli A et al.; Italian Diabetic Pregnancy Study Group (SID). Contraception in diabetic women: an Italian study. Diabetes Research and Clinical Practice, 2005, 67:267-272.

17. Wild $S$ et al. Global prevalence of diabetes: estimates for the year 2000 and projections for 2030. Diabetes Care, 2004, 27:1047-1053.

18. Mahmud M, Mazza D. Preconception care of women with diabetes: a review of current guideline recommendations. $B M C$ Women's Health, 2010, 10:5. 